Cronfa - Swansea University Open Access Repository

This is an author produced version of a paper published in :

Journal of Hypertension

Cronfa URL for this paper:

http://cronfa.swan.ac.uk/Record/cronfa30984

\title{
Paper:
}

Borghi, C., Rodriguez-Artalejo, F., De Backer, G., Dallongeville, J., Medina, J., Guallar, E., Perk, J., Banegas, J., Tubach, F., Roy, C. \& Halcox, J. (2016). The association between blood pressure and lipid levels in Europe. Journal of Hypertension, 34(11), 2155-2163.

http://dx.doi.org/10.1097/HJH.0000000000001078

This article is brought to you by Swansea University. Any person downloading material is agreeing to abide by the terms of the repository licence. Authors are personally responsible for adhering to publisher restrictions or conditions. When uploading content they are required to comply with their publisher agreement and the SHERPA RoMEO database to judge whether or not it is copyright safe to add this version of the paper to this repository. http://www.swansea.ac.uk/iss/researchsupport/cronfa-support/ 
The association between blood pressure and lipid levels in Europe:

EURIKA

Claudio BORGHI ${ }^{\mathrm{a}}$, Fernando RODRIGUEZ-ARTALEJO ${ }^{\mathrm{b}, \mathrm{c}}$, Guy De BACKER ${ }^{\mathrm{d}}$, Jean DALLONGEVILLE ${ }^{\mathrm{e}}$, Jesús MEDINA ${ }^{\mathrm{f}}$, Eliseo GUALLAR ${ }^{\mathrm{g}}$, Joep PERK ${ }^{\mathrm{h}}$, José R BANEGAS $^{\mathrm{b}, \mathrm{c}}$, Florence TUBACH ${ }^{\mathrm{i}, \mathrm{j}, \mathrm{k}}$, Carine ROY ${ }^{\mathrm{i}, \mathrm{j}}$, and Julian P HALCOX ${ }^{1}$

The final definitive version of this paper has been published in the Journal of Hypertension, November 2016 by Lippincott, Williams \& Wilkins All rights reserved.

doi: 10.1097/HJH.0000000000001078.

http://journals.lww.com/jhypertension/Abstract/2016/11000/The_association_between_blood_pressure _and_lipid.10.aspx 


\section{The association between blood pressure and lipid levels in Europe:}

\section{EURIKA}

Running head: Blood pressure and lipid levels

Claudio BORGHI ${ }^{\mathrm{a}}$, Fernando RODRIGUEZ-ARTALEJO ${ }^{\mathrm{b}, \mathrm{c}}$, Guy De BACKER ${ }^{\mathrm{d}}$, Jean DALLONGEVILLE ${ }^{\mathrm{e}}$, Jesús MEDINA ${ }^{\mathrm{f}}$, Eliseo GUALLAR ${ }^{\mathrm{g}}$, Joep PERK ${ }^{\mathrm{h}}$, José R BANEGAS $^{\mathrm{b}, \mathrm{c}}$, Florence TUBACH ${ }^{\mathrm{i}, \mathrm{j}, \mathrm{k}}$, Carine ROY ${ }^{\mathrm{i}, \mathrm{j}}$, and Julian P HALCOX ${ }^{1}$

a Department of Medical and Surgical Sciences, University of Bologna, Bologna, Italy; $\mathrm{b}_{\text {Department of Preventive Medicine and Public Health, School of Medicine, Universidad }}$ Autónoma de Madrid/IdiPaz, Madrid, Spain; ${ }^{\mathrm{c}}$ CIBER of Epidemiology and Public Health (CIBERESP), Instituto de Salud Carlos III, Madrid, Spain; dDepartment of Public Health, Ghent University, Ghent, Belgium; ${ }^{\mathrm{e}}$ INSERM U 744, Institut Pasteur de Lille, Université Lille-Nord de France, Lille, France; ${ }^{\mathrm{f}}$ Medical Evidence and Observational Research, Global Medical Affairs, AstraZeneca Farmacéutica Spain, Madrid, Spain; ${ }^{\mathrm{g}}$ Departments of Epidemiology and Medicine and Welch Center for Prevention, Epidemiology and Clinical Research, Johns Hopkins Bloomberg School of Public Health, Baltimore, MD, USA;

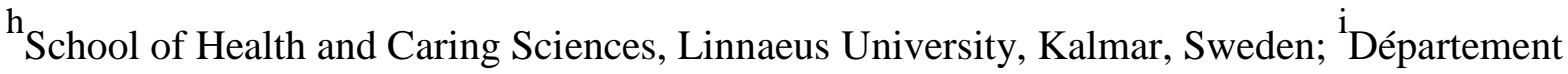
d'Épidémiologie et Recherche Clinique, Assistance Publique - Hôpitaux de Paris, Hôpital Bichat, Paris, France; ${ }^{j}$ INSERM, CIC-EC 1425, ECEVE, UMR 1123, Paris, France and Département d'Épidémiologie et Recherche Clinique, Centre de pharmacoépidémiologie (Cephepi), Assistance Publique - Hôpitaux de Paris, Hôpital Bichat, Paris, France; kUniversité Paris Diderot, Sorbonne Paris Cité, ECEVE, UMR 1123, Paris, France; ${ }^{1}$ Swansea University School of Medicine, Swansea, UK 


\section{Funding}

EURIKA was funded by AstraZeneca. The study was overseen by an independent academic steering committee. The authors had full access to all data and had final responsibility for the contents of the manuscript and the decision to submit it for publication.

\section{Conflicts of interest}

Claudio Borghi has received speaker and consulting fees from Menarini, Merck Sharp \& Dohme, Servier and Takeda. Jean Dallongeville and Julian P Halcox have received speaker and consulting fees from AstraZeneca. Jesús Medina is an employee of AstraZeneca. Eliseo Guallar and Florence Tubach have received payment for statistical analysis work from AstraZeneca. For the remaining authors no competing interests are declared.

\section{Corresponding author}

Professor Claudio Borghi, Department of Medical and Surgical Sciences, S. Orsola-Malpighi University Hospital, Via Albertoni 15 - Pad. 2, 40138 Bologna, Italy. Tel: +39 0516362843; fax: +39 051391320; e-mail: claudio.borghi@unibo.it

Word count (including references): 4195

Word count (abstract): 245

Number of tables: 3

Number of figures: 2

Number of supplementary digital content files: 1 supplementary table 


\begin{abstract}
Objectives: Several studies have suggested a positive association between serum lipid levels and blood pressure (BP). This study investigated this association in a large population from 12 European countries.
\end{abstract}

Methods: Data were taken from the European Study on Cardiovascular Risk Prevention and Management in Usual Daily Practice (EURIKA; ClinicalTrials.gov identifier:

NCT00882336). Associations between BP and lipid levels in patients free from cardiovascular disease (CVD) and with at least one major CVD risk factor $(N=7641)$ were assessed using linear regression analyses.

Results: Overall, $72.8 \%$ and $64.8 \%$ of patients had hypertension and dyslipidaemia, respectively; $47.0 \%$ had both conditions. Regression coefficients (95\% confidence interval [CI]) for the associations of low-density lipoprotein cholesterol, non-high-density lipoprotein cholesterol, total cholesterol and apolipoprotein B levels with systolic BP, adjusted for age, sex and body mass index, were $0.93 \mathrm{mmHg} / \mathrm{mmol} / \mathrm{L}(0.54$ to 1.31$), 1.07$ $\mathrm{mmHg} / \mathrm{mmol} / \mathrm{L}$ (0.73 to 1.40$), 1.02 \mathrm{mmHg} / \mathrm{mmol} / \mathrm{L}(0.69$ to 1.35$)$ and $4.94 \mathrm{mmHg} / \mathrm{g} / \mathrm{L}$ (3.43 to 6.46), respectively. The corresponding values $(95 \% \mathrm{CI})$ for the associations with diastolic BP were $0.96 \mathrm{mmHg} / \mathrm{mmol} / \mathrm{L}$ (0.73 to 1.19$), 0.95 \mathrm{mmHg} / \mathrm{mmol} / \mathrm{L}$ (0.75 to 1.15$), 0.87$ $\mathrm{mmHg} / \mathrm{mmol} / \mathrm{L}$ (0.67 to 1.07 ) and $4.33 \mathrm{mmHg} / \mathrm{g} / \mathrm{L}$ (3.42 to 5.23), respectively. Most of these associations remained significant whether patients were treated with statins or not. Conclusions: Small but statistically significant associations between lipid levels and BP were observed in a large, multinational European population. Further research is warranted to assess the causality of this association and its implications on the management of patients with both hypertension and dyslipidaemia.

Keywords: blood pressure, cholesterol, dyslipidaemia, hypertension 


\section{Abbreviations}

ACE, angiotensin-converting enzyme; apo-A1, apolipoprotein A1; apo-B, apolipoprotein B; AT1, angiotensin II type 1; BMI, body mass index; BP, blood pressure; CHD, coronary heart disease; CI, confidence interval; CVD, cardiovascular disease; DBP, diastolic blood pressure; EURIKA, European Study on Cardiovascular Risk Prevention and Management in Usual Daily Practice; HDL-C, high-density lipoprotein cholesterol; LDL-C, low-density lipoprotein cholesterol ; SBP, systolic blood pressure 


\section{INTRODUCTION}

Dyslipidaemia and hypertension are two of the principal, established, modifiable risk factors for cardiovascular disease (CVD) and coexist in a substantial proportion of patients [1-3]. It has also been shown that the coronary heart disease (CHD) risk in patients with hypertension and dyslipidaemia is greater than the sum of CHD risks for hypertension and dyslipidaemia when they occur alone [4], thereby supporting a degree of clinical interaction between the two risk factors. Despite recent improvements in the understanding and treatment of cardiovascular risk factors [5-7], control of both serum lipid levels and blood pressure (BP) remains suboptimal [8-13].

As part of the recent European Study on Cardiovascular Risk Prevention and Management in Usual Daily Practice (EURIKA; ClinicalTrials.gov identifier: NCT00882336), a study of the primary prevention of CVD in Europe, we have shown that only $41.2 \%$ of patients with no history of CVD and being treated for dyslipidaemia attained both total cholesterol and lowdensity lipoprotein cholesterol (LDL-C) targets of $<5$ and $<3 \mathrm{mmol} / \mathrm{L}$, respectively [8]. Similarly, only $38.8 \%$ of these patients being treated for hypertension achieved the BP target of $<140 / 90 \mathrm{mmHg}$, as recommended by the most recent European guidelines [14]. The high proportion of patients unable to achieve satisfactory control of both serum lipid levels and hypertension suggests that there may be an interaction between the two risk factors. Indeed, several studies have shown that there may be a positive association between elevated serum lipid levels and hypertension $[15,16]$ and that better lipid control may lead to a lower incidence of new-onset hypertension $[17,18]$.

Statins are the mainstay of cholesterol-lowering drug therapy. Although the primary function of statins is to reduce cholesterol levels, it has been suggested that they may also have a mild, but clinically relevant, BP-lowering effect, particularly in patients with poorly controlled 
hypertension [19-21]. Moreover, several pathophysiological mechanisms may account for the association between BP and serum lipid profile, including overexpression of angiotensin II type 1 (AT1) receptors and non-angiotensin-converting enzyme (non-ACE)-mediated upregulation of angiotensin II production as a result of elevated serum lipid levels [22-25].

Although several studies have reported an association between BP and serum lipid levels, most were published more than 10 years ago [15,26,27], included small numbers of individuals $[16,18,27]$, were conducted in specific countries or cities $[1,15,16,18,26,27]$, did not stratify the results according to statin treatment status $[1,15,16,18,26]$ or were population based and did not focus on the clinical setting $[1,15,16,18,27]$. In order to provide a contemporary and comprehensive assessment of the association between BP and dyslipidaemia in usual clinical practice across several European countries in patients with varying degrees of CVD risk, we performed a secondary analysis of data from EURIKA.

\section{METHODS}

\section{Study design and participants}

EURIKA was conducted in 12 European countries (Austria, Belgium, France, Germany, Greece, Norway, Russia, Spain, Sweden, Switzerland, Turkey and the United Kingdom) [8]. Data collection started in May 2009 and ended in January 2010, with a 3-month datacollection period for each country. The study protocol was approved by the appropriate clinical research ethics committee in each participating country, and all patients provided signed informed consent. The methods for the study have been reported in detail elsewhere [28]. Briefly, the study recruited patients with at least one risk factor for CVD, but no history of cardiovascular events. The study sample was selected in a two-step process that involved recruitment of physicians and their patients [28,29]. In the first stage, a random sample of 
primary care physicians and specialists involved in CVD prevention, stratified by age, sex and specialty, were selected for invitation to participate using the OneKey database (Cegedim Dendrite, Boulogne-Billancourt, France). The percentage of participating physicians among those invited was $7.9 \%$ [28]. In all countries, primary care physicians were the predominant type of physician, making up 64\% of physicians overall [28]. In total, 809 physicians (approximately 60 per country) agreed to participate in EURIKA [29]. In the second stage, participating physicians sequentially invited patients who met the selection criteria (age 50 years or older, free of CVD but having at least one major cardiovascular risk factor [8]. The major cardiovascular risk factors were: dyslipidaemia; hypertension; smoking (current or former smoker, with >100 cigarettes smoked in lifetime); diabetes mellitus (fasting plasma glucose $\geq 7.0 \mathrm{mmol} / \mathrm{L}[126 \mathrm{mg} / \mathrm{dL}]$ or receiving antidiabetic medication [insulin or oral medications]); obesity (body mass index [BMI] $\geq 30 \mathrm{~kg} / \mathrm{m}^{2}$ or waist circumference $\geq 102 \mathrm{~cm}$ in men and $\geq 88 \mathrm{~cm}$ in women) [28]. Approximately 12,300 patients were invited to participate, of whom 7641 (about 600 patients per country) accepted [8].

\section{Assessment of CVD risk factors}

Demographic information and other details of participating patients were gathered from medical records and patient interviews. For each patient, a physical examination was conducted, BP was measured, and a 12-hour fasting blood sample was collected within 1 day of the initial outpatient consultation.

BP measurements were obtained under standardized conditions, using calibrated mercury sphygmomanometers or validated automated devices and appropriate-sized cuffs. The mean of three consecutive measurements in the sitting position and spaced 1-2 minutes apart was used for the analyses [14]. Blood sample analysis was performed by a central laboratory (BioAnalytical Research Corporation, Ghent, Belgium) for samples from all patients except 
those in Russia (approximately 5\% of all patients), for which laboratory analysis was conducted locally.

High-density lipoprotein cholesterol (HDL-C) concentration was measured by a modified enzymatic method and total cholesterol concentration by the glycerophosphate oxidaseperoxidase-4-aminophenazone (GPO-PAP) method (using the Roche Modular P Chemistry Analyzer [Roche Diagnostics, Indianapolis, IN, USA]). LDL-C concentration was calculated by the Friedewald formula [30]. Apolipoprotein A1 (apo-A1) and apolipoprotein B (apo-B) concentrations were measured using immunoturbidimetric methods.

\section{Definition of blood pressure and serum lipid level status}

BP status was defined as follows: normotensive (systolic BP [SBP] $<120 \mathrm{mmHg}$ and diastolic $\mathrm{BP}[\mathrm{DBP}]<80 \mathrm{mmHg}$ and not receiving antihypertensive medication); normal-tohigh-normal BP (SBP 120 to $<140 \mathrm{mmHg}$ and DBP 80 to $<90 \mathrm{mmHg}$ and not receiving antihypertensive medication); hypertensive ( $\mathrm{SBP} \geq 140 \mathrm{mmHg}$ and/or $\mathrm{DBP} \geq 90 \mathrm{mmHg}$ or being treated with one or more antihypertensive drugs) [31].

Patients were defined as having dyslipidaemia if they had a serum LDL-C concentration $\geq 4.9 \mathrm{mmol} / \mathrm{L}(190 \mathrm{mg} / \mathrm{dL})$, a serum HDL-C concentration $<1.0 \mathrm{mmol} / \mathrm{L}$ (40 mg/dL) for men or $<1.3 \mathrm{mmol} / \mathrm{L}(50 \mathrm{mg} / \mathrm{dL})$ for women, a serum non-HDL-C concentration $\geq 5.2 \mathrm{mmol} / \mathrm{L}$ $(200 \mathrm{mg} / \mathrm{dL})$ for men or $\geq 4.9 \mathrm{mmol} / \mathrm{L}(190 \mathrm{mg} / \mathrm{dL})$ for women, or if they were receiving lipid-lowering medication [32].

\section{Statistical analyses}

Statistical analyses were performed using SAS V9.2 (SAS Institute, Inc., Cary, NC, USA). Associations between BP (SBP, DBP and pulse pressure) and serum lipid levels were assessed using multivariate linear regression analyses. In a first model (model A), estimates 
were adjusted for age, sex and BMI. Associations were also assessed with a model further adjusted for statin use, antihypertensive treatment (yes/no), number of cardiovascular risk factors (among smoking, diabetes and dyslipidaemia), physical activity and country (model B). Statistical significance was defined as two-sided $P<0.05$. For analyses stratified by statin use, estimates were adjusted for model A variables plus antihypertensive treatment (yes/no), physical activity and country.

\section{RESULTS}

\section{Patient demographics and general characteristics}

The characteristics of the 7641 patients in the EURIKA study population are presented in Table 1. The mean age of subjects was 63.2 years, and there were more women $(51.6 \%)$ than men $(48.4 \%)$. The overall proportion of patients with hypertension was $72.8 \%$, with a notable difference between countries (Supplementary Table 1). The countries with the highest and the lowest proportions of individuals with hypertension were Sweden (82.2\%) and Austria (61.4\%), respectively. Overall, 5239 patients (68.6\%) were receiving antihypertensive medications, with the most common treatments being diuretics, angiotensin II antagonists and ACE inhibitors (Table 2).

The prevalence of dyslipidaemia was $64.8 \%$, with a between-countries range of $57.5 \%-$ 73.7\%. Austria had the lowest proportion of patients with dyslipidaemia and Greece the highest. Patients with both hypertension and dyslipidaemia accounted for $47.0 \%$ of the study participants (between-countries range: $41.0 \%-58.4 \%$ ). The mean serum concentrations of LDL-C, HDL-C, total cholesterol and apo-B were 3.2, 1.4 and $5.5 \mathrm{mmol} / \mathrm{L}$ and $0.9 \mathrm{~g} / \mathrm{L}$, respectively. 


\section{Relationship between blood pressure and serum lipid profile}

In order to determine the relationship between BP (SBP and DBP) and serum lipid levels (LDL-C, HDL-C, non-HDL-C, total cholesterol, apo-A1 and apo-B), scatterplots with regression lines were created for all patients for whom data were available (Figures 1 and 2). When adjusted for age, sex and BMI, linear regression analyses (model A) showed that LDL-C, non-HDL-C, total cholesterol, apo-A1 and apo-B levels were significantly associated with SBP, and that LDL-C, non-HDL-C, total cholesterol and apo-B levels were significantly associated with DBP (Table 3). Similar results were observed when the regression analyses were further adjusted for use of statins, antihypertensive treatment, number of cardiovascular risk factors, physical activity and study country (model B).

When stratifying the analyses by statin use, the aforementioned associations, adjusted for age, sex, BMI, antihypertensive treatment, physical activity and study country, remained significant, and the associations between apo-A1 and DBP in patients not treated with a statin became significant (Table 4).

\section{Relationship between pulse pressure and serum lipid profile}

Scatterplots with regression lines were created to determine the relationship between pulse pressure (SBP minus DBP) and serum lipid levels (Figure 3). Linear regression analyses adjusted for model B showed that HDL-C, total cholesterol and apo-A1 were significantly associated with pulse pressure (Table 5). When stratifying the analyses by statin use, none of the aforementioned associations, adjusted for age, sex, BMI, antihypertensive treatment, physical activity and study country, remained significant when only patients treated with statins were considered. The associations between total cholesterol, apo-A1 and pulse pressure remained significant when only patients not treated with statins were considered (Table 5). 


\section{DISCUSSION}

The present study has shown a small but statistically significant positive association between serum lipid levels (LDL-C, total cholesterol, non-HDL-C and apo-B) and BP in a large sample of patients with at least one risk factor for CVD but no history of CVD who were enrolled in a setting of day-to-day clinical practice. The relationship between BP and serum lipid profile involves both SBP and DBP, and is independent of statin use, antihypertensive treatment and number of cardiovascular risk factors. A similar association has been previously described in both the Troms $\varnothing$ Study [15] and the Brisighella Heart Study [16]. The Troms $\varnothing$ Study showed that non-HDL-C levels increased significantly with increasing SBP and DBP [15]. Similarly, in the Brisighella Heart Study, LDL-C and apo-B serum levels appeared to be significantly related to SBP and DBP [16]. For example, in a model adjusted for age, sex, BMI, smoking habit, physical activity level and serum creatinine, apo-B appeared to be significantly positively related to both SBP (unstandardized coefficient 0.166 $\mathrm{mmHg} / \mathrm{mg} / \mathrm{dL} ; 95 \%$ confidence interval $[\mathrm{CI}] 0.133$ to $0.198 ; P<0.001)$ and DBP (unstandardized coefficient $0.071 \mathrm{mmHg} / \mathrm{mg} / \mathrm{dL} ; 95 \%$ CI 0.051 to $0.090 ; P<0.001$ ). Analogously, in EUROASPIRE III, a survey of patients previously hospitalized for coronary heart disease, a negative association was observed between dyslipidaemia and BP control in individuals using antihypertensive medication [33]. Our results are also in line with recent findings that higher LDL-C levels are associated with a higher incidence of new-onset hypertension $[17,18]$. These data support the hypothesis that dyslipidaemia may contribute significantly to the onset and progression of hypertension.

The association between serum lipid levels and BP is corroborated by the results of a recent meta-analysis of 40 prospective controlled studies involving a total of 45,113 patients, which showed a small reduction in mean SBP $(2.62 \mathrm{mmHg} ; 95 \% \mathrm{CI} 1.84$ to $3.41 ; P<0.001)$ and in 
mean DBP $(0.94 \mathrm{mmHg} ; 95 \%$ CI 0.57 to $1.31 ; P<0.001)$ in patients treated with statins compared with those not treated with statins [19]. The positive effect of statins on BP was slightly greater in hypertensive patients than in normotensive patients. Furthermore, a recent study that included data from two separate interventional studies in hypertensive and diabetic individuals consistently showed that statin use was associated with lower BP and reduced aldosterone levels [21]. Lower aldosterone levels at higher statin doses indicated a doseresponse effect for statin use [21]. Additionally, ex vivo experiments confirmed that statins blocked potassium-stimulated production of aldosterone, suggesting that statins act downstream from the AT1 receptor to decrease aldosterone production [21].

From a practical point of view, the BP changes associated with the modifications of serum lipid profile can have a measurable impact on cardiovascular risk profile [14]. A BP increase of a few mmHg in the general population has been associated with an increase in the risk of fatal and non-fatal coronary artery disease and stroke in both normotensive and hypertensive patients [34]. Conversely, a reduction in BP of the magnitude observed in patients under statin treatment may have a significant impact on the prevention of CVD at a population level. Results from an overview of observational studies and randomized trials suggest that a $2 \mathrm{mmHg}$ reduction in DBP would result in a 17\% decrease in the prevalence of hypertension as well as a $6 \%$ reduction in the risk of coronary heart disease and a $15 \%$ reduction in the risk of stroke and transient ischaemic attack [35]. These findings highlight the importance of improving lipid control in the general population, with the aim of reducing the burden of CVD attributable to elevated BP.

Several pathophysiological mechanisms have been suggested to explain the observed association between dyslipidaemia and hypertension. A potential explanation is that elevated LDL-C levels can progressively impair endothelial function and promote vascular stiffness, 
thus leading to an increase in BP. Patients in EURIKA were free of overt CVD, and the possibility of a high prevalence of atherosclerotic disease in this population is unlikely. However, total cholesterol and apo-A1 were significantly associated with pulse pressure overall and in patients not treated with statins, although not in patients treated with statins. Alternatively, more complex mechanisms may explain the effect of dyslipidaemia on BP. In particular, several studies have suggested that high levels of LDL-C may increase instability of mRNA for AT1 receptors [22,36,37], leading to overexpression of AT1 receptors in vascular tissues. Activation of these receptors by angiotensin II results in an enhanced vasoconstrictive response that might contribute to the development of hypertension and atherosclerotic disease, an effect has also been described in vivo [38-40]. In addition, angiotensin II promotes the oxidation of LDL-C, with increased levels of oxidized LDL-C also contributing to overexpression of AT1 receptors [41]. Beyond direct effects of LDL-C on AT1 receptors, it has also been suggested that dyslipidaemia may increase the chymasedependent production of angiotensin II [24,42]. This increase in ACE-independent production of angiotensin II may act synergistically with upregulation of AT1 receptors in hypercholesterolaemic patients, which would explain the observed correlation between serum lipid levels and BP.

Regardless of the mechanism involved, the evidence of a significant association between elevated LDL-C and BP highlights the importance of controlling serum lipid levels in the general population and in patients with hypertension in particular, who may benefit from a more intensive statin treatment regimen.

\section{Strengths and limitations}

Particular strengths of our study include a large sample of patients from multiple countries, the collection of data with standardized procedures and a reliable data set provided by the use 
of a central laboratory for analyses of serum lipid levels. A limitation inherent in the observational study design is that the causal contributions of pathophysiological mechanisms are not elucidated. Furthermore, the cross-sectional design of the study does not allow the direction of the association between serum lipid levels and BP to be established. It should also be noted that in linear regression analyses, several parameters that may affect BP and/or serum lipid levels, such as dietary habits, were not taken into account. Also, although analyses were adjusted for antihypertensive treatment (yes/no) and for number of cardiovascular risk factors, they were not adjusted separately for class of antihypertensive treatment or type of cardiovascular risk factor, and relationships between BP and lipid levels were not assessed separately in hypertensive participants. Furthermore, information on medication adherence was not available and could thus not be taken into consideration. Although further research is required to determine whether there is a causal relationship between serum lipid levels and BP, our results suggest that dyslipidaemia should be carefully assessed and managed in patients with hypertension.

\section{CONCLUSION}

In this study, we have observed a significant association between serum lipid levels and BP in a large, multinational, European, primary CVD prevention population. Our results are in agreement with those of previously conducted studies $[15,16]$. Given the high concomitant prevalence of hyperlipidaemia and hypertension observed in this and other studies [2,3], further research is warranted to assess the BP-lowering effect of statins in addition to standard hypertensive treatment and to develop more effective multidisciplinary management of patients with both dyslipidaemia and hypertension. 


\section{ACKNOWLEDGMENTS}

Writing support was provided by Stéphane Pintat (PhD) of Oxford PharmaGenesis, Oxford, UK, and was funded by AstraZeneca. 


\section{REFERENCES}

1. De Bacquer D, De Backer G. The prevalence of concomitant hypertension and hypercholesterolaemia in the general population. Int J Cardiol. 2006; 110: 217-23.

2. Egan BM, Li J, Qanungo S, Wolfman TE. Blood pressure and cholesterol control in hypertensive hypercholesterolemic patients: National Health and Nutrition Examination Surveys 1988-2010. Circulation. 2013; 128: 29-41.

3. Kabakci G, Koylan N, Ilerigelen B, Kozan O, Buyukozturk K. Impact of dyslipidemia on cardiovascular risk stratification of hypertensive patients and association of lipid profile with other cardiovascular risk factors: results from the ICEBERG study. Integr Blood Press Control. 2008; 1: 5-13.

4. Neaton JD, Wentworth D. Serum cholesterol, blood pressure, cigarette smoking, and death from coronary heart disease. Overall findings and differences by age for 316,099 white men. Multiple Risk Factor Intervention Trial Research Group. Arch Intern Med. 1992; 152: 56-64.

5. Akesson A, Weismayer C, Newby PK, Wolk A. Combined effect of low-risk dietary and lifestyle behaviors in primary prevention of myocardial infarction in women. Arch Intern Med. 2007; 167: 2122-7.

6. Unal B, Critchley JA, Capewell S. Modelling the decline in coronary heart disease deaths in England and Wales, 1981-2000: comparing contributions from primary prevention and secondary prevention. BMJ. 2005; 331: 614.

7. Perk J, De Backer G, Gohlke H, Graham I, Reiner Z, Verschuren M, et al. European guidelines on cardiovascular disease prevention in clinical practice (version 2012): The Fifth Joint Task Force of the European Society of Cardiology and Other Societies on Cardiovascular Disease Prevention in Clinical Practice (constituted by representatives of nine societies and by invited experts). Eur Heart J. 2012; 33: 1635 701.

8. Banegas JR, Lopez-Garcia E, Dallongeville J, Guallar E, Halcox JP, Borghi C, et al. Achievement of treatment goals for primary prevention of cardiovascular disease in clinical practice across Europe: the EURIKA study. Eur Heart J. 2011; 32: 2143-52.

9. Hermans MP, Van Mieghem W, Vandenhoven G, Vissers E. Centralized PanEuropean survey on the undertreatment of hypercholesterolaemia (CEPHEUS). Acta Cardiologica. 2009; 64: 177-85. 
10. Schelleman H, Klungel OH, Kromhout D, de Boer A, Stricker BH, Verschuren WM. Prevalence and determinants of undertreatment of hypertension in the Netherlands. $\mathbf{J}$ Hum Hypertens. 2004; 18: 317-24.

11. Firmann M, Marques-Vidal P, Paccaud F, Mooser V, Rodondi N, Waeber G, et al. Prevalence, treatment and control of dyslipidaemia in Switzerland: still a long way to go. Eur J Cardiovasc Prev Rehabil. 2010; 17: 682-7.

12. Guallar-Castillon P, Gil-Montero M, Leon-Munoz LM, Graciani A, Bayan-Bravo A, Taboada JM, et al. Magnitude and management of hypercholesterolemia in the adult population of Spain, 2008-2010: the ENRICA study. Rev Esp Cardiol (Engl Ed). 2012; 65: 551-8.

13. Wolf-Maier K, Cooper RS, Kramer H, Banegas JR, Giampaoli S, Joffres MR, et al. Hypertension treatment and control in five European countries, Canada, and the United States. Hypertension. 2004; 43: 10-7.

14. Mancia G, Fagard R, Narkiewicz K, Redon J, Zanchetti A, Bohm M, et al. 2013 ESH/ESC guidelines for the management of arterial hypertension: the Task Force for the Management of Arterial Hypertension of the European Society of Hypertension (ESH) and of the European Society of Cardiology (ESC). Eur Heart J. 2013; 34: 2159-219.

15. Bonaa KH, Thelle DS. Association between blood pressure and serum lipids in a population. The Troms $\varnothing$ Study. Circulation. 1991; 83: 1305-14.

16. Cicero AFG, D’Addato S, Veronesi M, Rosticci M, Santi F, Dormi A, et al. Relationship between blood pressure, cholesterolemia and serum apolipoprotein B in a large population sample: the Brisighella Heart Study. J Hypertens. 2012; 30: 492-6.

17. Borghi C, Cicero AF, Saragoni S, Buda S, Cristofori C, Lilli P, et al. Rate of control of LDL cholesterol and incident hypertension requiring antihypertensive treatment in hypercholesterolemic subjects in daily clinical practice. Ann Med. 2014; 46: 97-102.

18. Cicero A, Rosticci M, Baronio C, Morbini M, Parini A, Grandi E, et al. Serum LDL Cholesterol levels and new-onset of arterial hypertension: an 8-year follow-up. Eur J Clin Invest. 2014; 44: 926-32.

19. Briasoulis A, Agarwal V, Valachis A, Messerli FH. Antihypertensive effects of statins: a meta-analysis of prospective controlled studies. J Clin Hypertens. 2013; 15 : $310-20$. 
20. Strazzullo P, Kerry SM, Barbato A, Versiero M, D'Elia L, Cappuccio FP. Do statins reduce blood pressure?: a meta-analysis of randomized, controlled trials. Hypertension. 2007; 49: 792-8.

21. Baudrand R, Pojoga LH, Vaidya A, Garza AE, Vohringer PA, Jeunemaitre X, et al. Statin Use and Adrenal Aldosterone Production in Hypertensive and Diabetic Subjects. Circulation. 2015; 132: 1825-33.

22. Strehlow K, Wassmann S, Bohm M, Nickenig G. Angiotensin AT1 receptor over-expression in hypercholesterolaemia. Ann Med. 2000; 32: 386-9.

23. Nickenig G, Wassmann S, Bohm M. Regulation of the angiotensin AT1 receptor by hypercholesterolaemia. Diabetes Obes Metab. 2000; 2: 223-8.

24. Murakami K, Uehara Y, Abe S, Inoue Y, Ideishi M, Saku K, et al. Positive correlation between chymase-like angiotensin II-forming activity in mononuclear cells and serum cholesterol level. J Cardiol. 2007; 50: 291-8.

25. Borghi C, Veronesi M, Cosentino E, Cicero AF, Kuria F, Dormi A, et al. Interaction between serum cholesterol levels and the renin-angiotensin system on the new onset of arterial hypertension in subjects with high-normal blood pressure. J Hypertens. 2007; 25: 2051-7.

26. Selby JV, Peng T, Karter AJ, Alexander M, Sidney S, Lian J, et al. High rates of cooccurrence of hypertension, elevated low-density lipoprotein cholesterol, and diabetes mellitus in a large managed care population. Am J Manag Care. 2004; 10: 163-70.

27. O'Meara JG, Kardia SL, Armon JJ, Brown CA, Boerwinkle E, Turner ST. Ethnic and sex differences in the prevalence, treatment, and control of dyslipidemia among hypertensive adults in the GENOA study. Arch Intern Med. 2004; 164: 1313-8.

28. Rodriguez-Artalejo F, Guallar E, Borghi C, Dallongeville J, De Backer G, Halcox JP, et al. Rationale and methods of the European Study on Cardiovascular Risk Prevention and Management in Daily Practice (EURIKA). BMC Public Health. 2010; 10: 382 .

29. Dallongeville J, Banegas JR, Tubach F, Guallar E, Borghi C, De Backer G, et al. Survey of physicians' practices in the control of cardiovascular risk factors: the EURIKA study. Eur J Cardiovasc Prev Rehabil. 2011; 19: 541-50.

30. Friedewald WT, Levy RI, Fredrickson DS. Estimation of the concentration of lowdensity lipoprotein cholesterol in plasma, without use of the preparative ultracentrifuge. Clin Chem. 1972; 18: 499-502. 
31. Chobanian AV, Bakris GL, Black HR, Cushman WC, Green LA, Izzo JL, Jr., et al. The seventh report of the Joint National Committee on Prevention, Detection, Evaluation, and Treatment of High Blood Pressure: the JNC 7 report. JAMA. 2003; 289: 2560-72.

32. Executive summary of the third report of the National Cholesterol Education Program (NCEP) expert panel on detection, evaluation, and treatment of high blood cholesterol in adults (Adult Treatment Panel III). JAMA. 2001; 285: 2486-97.

33. Prugger C, Keil U, Wellmann J, de Bacquer D, de Backer G, Ambrosio GB, et al. Blood pressure control and knowledge of target blood pressure in coronary patients across Europe: results from the EUROASPIRE III survey. J Hypertens. 2011; 29: 1641-8.

34. Lewington S, Clarke R, Qizilbash N, Peto R, Collins R. Age-specific relevance of usual blood pressure to vascular mortality: a meta-analysis of individual data for one million adults in 61 prospective studies. Lancet. 2002; 360: 1903-13.

35. Cook NR, Cohen J, Hebert PR, Taylor JO, Hennekens CH. Implications of small reductions in diastolic blood pressure for primary prevention. Arch Intern Med. 1995; 155: 701-9.

36. Nickenig G, Jung O, Strehlow K, Zolk O, Linz W, Scholkens BA, et al. Hypercholesterolemia is associated with enhanced angiotensin AT1-receptor expression. Am J Physiol. 1997; 272: H2701-H7.

37. Nickenig G, Sachinidis A, Michaelsen F, Bohm M, Seewald S, Vetter H. Upregulation of vascular angiotensin II receptor gene expression by low-density lipoprotein in vascular smooth muscle cells. Circulation. 1997; 95: 473-8.

38. Castejon AM, Zollner E, Tristano AG, Cubeddu LX. Upregulation of angiotensin IIAT1 receptors during statin withdrawal in vascular smooth muscle cells. J Cardiovasc Pharmacol. 2007; 50: 708-11.

39. Wassmann S, Nickenig G, Böhm M. Atorvastatin downregulates AT1-receptor gene expression and cell proliferation in vascular smooth muscle cells. J Am Coll Cardio. 1999; 33: 222A-3A.

40. Yang BC, Phillips MI, Mohuczy D, Meng H, Shen L, Mehta P, et al. Increased angiotensin II type 1 receptor expression in hypercholesterolemic atherosclerosis in rabbits. Arterioscler Thromb Vasc Biol. 1998; 18: 1433-9. 
41. Li D, Singh RM, Liu L, Chen H, Singh BM, Kazzaz N, et al. Oxidized-LDL through LOX-1 increases the expression of angiotensin converting enzyme in human coronary artery endothelial cells. Cardiovasc Res. 2003; 57: 238-43.

42. Uehara Y, Urata H, Sasaguri M, Ideishi M, Sakata N, Tashiro T, et al. Increased chymase activity in internal thoracic artery of patients with hypercholesterolemia. Hypertension. 2000; 35: 55-60. 
TABLE 1. Socio-demographic and clinical characteristics of patients in EURIKA $(N=7641)$

Characteristic Overall $(N=7641)$

\begin{tabular}{|c|c|}
\hline Age (years) & $63.2(9.0)$ \\
\hline \multicolumn{2}{|l|}{ Sex } \\
\hline Men, $n(\%)$ & $3696(48.4)$ \\
\hline Women, $n(\%)$ & $3945(51.6)$ \\
\hline $\mathrm{SBP}(\mathrm{mmHg})$ & $135.1(16.6)$ \\
\hline $\mathrm{DBP}(\mathrm{mmHg})$ & $80.9(9.9)$ \\
\hline Normotensive, $n(\%)$ & $701(9.2)$ \\
\hline Normal-to-high-normal BP, $n(\%)$ & $1359(17.9)$ \\
\hline Hypertensive, $n(\%)$ & $5559(72.8)$ \\
\hline Dyslipidaemia, $n(\%)$ & $4948(64.8)$ \\
\hline Hypertension and dyslipidaemia, $n(\%)$ & $3593(47.0)$ \\
\hline LDL-C (mmol/L) & $3.2(1.0)$ \\
\hline HDL-C (mmol/L) & $1.4(0.4)$ \\
\hline Non-HDL-C (mmol/L) & $4.0(1.1)$ \\
\hline $\mathrm{TC}(\mathrm{mmol} / \mathrm{L})$ & $5.5(1.1)$ \\
\hline Apo-A1 (g/L) & $1.5(0.3)$ \\
\hline Apo-B (g/L) & $0.9(0.2)$ \\
\hline
\end{tabular}

Data are mean (SD) unless otherwise stated. Apo-A1, apolipoprotein A1; Apo-B, apolipoprotein B; BP, blood pressure; DBP, diastolic blood pressure; EURIKA, European Study on Cardiovascular Risk Prevention and Management in Usual Daily Practice; HDLC, high-density lipoprotein cholesterol; LDL-C, low-density lipoprotein cholesterol; SBP, systolic blood pressure; SD, standard deviation; TC, total cholesterol. 
TABLE 2. Treatment characteristics in patients in EURIKA receiving antihypertensive treatment $(n=5239)$

Patients receiving antihypertensive treatment

$(n=5239)$

Number of antihypertensive drugs

1 $2041(39.0)$

2

$1903(36.3)$

3

$920(17.6)$

$\geq 4$

$375(7.1)$

Type of antihypertensive drug

Angiotensin II antagonists

Anti-adrenergic agents

Beta-blocking agents

Calcium channel blockers

Diuretics

ACE inhibitors

Alpha-adrenergic antagonist

Other antihypertensive agent
$2121(40.5)$

$27(0.5)$

$1787(34.1)$

$1560(29.8)$

$2397(45.8)$

$1912(36.5)$

166(3.2)

$223(4.3)$

Data are n (\%). ACE, angiotensin-converting enzyme; EURIKA, European Study on Cardiovascular Risk Prevention and Management in Usual Daily Practice. 
TABLE 3. Relationship between blood pressure and serum lipid profile for patients in EURIKA

Model A $\mathbf{A}^{\mathbf{a}}$

Model B ${ }^{\mathbf{b}}$

Regression coefficient

(95\% CI)
$P$ value
Regression coefficient

(95\% CI)

Association with SBP

$\begin{array}{llll}\text { LDL-C } & 0.93(0.54 \text { to } 1.31)^{\mathrm{d}} & \mathbf{< 0 . 0 0 0 1} & 0.95(0.56 \text { to } 1.34)^{\mathrm{d}} \\ \text { HDL-C } & -0.21(-1.20 \text { to } 0.78)^{\mathrm{d}} & 0.6786 & 0.40(-0.57 \text { to } 1.38)^{\mathrm{d}} \\ \text { Non-HDL-C } & 1.07(0.73 \text { to } 1.40)^{\mathrm{d}} & <\mathbf{0 . 0 0 0 1} & 1.06(0.72 \text { to } 1.39)^{\mathrm{d}} \\ \text { Total cholesterol } & 1.02(0.69 \text { to } 1.35)^{\mathrm{d}} & <\mathbf{0 . 0 0 0 1} & 1.08(0.75 \text { to } 1.41)^{\mathrm{d}} \\ \text { Apo-A1 } & 1.66(0.23 \text { to } 3.10)^{\mathrm{e}} & \mathbf{0 . 0 2 3 3} & 2.45(1.04 \text { to } 3.85)^{\mathrm{e}} \\ \text { Apo-B } & 4.94(3.43 \text { to } 6.46)^{\mathrm{e}} & \mathbf{< 0 . 0 0 0 1} & 4.85(3.35 \text { to } 6.35)^{\mathrm{e}}\end{array}$

Association with DBP

$\begin{array}{llll}\text { LDL-C } & 0.96(0.73 \text { to } 1.19)^{\mathrm{d}} & \mathbf{< 0 . 0 0 0 1} & 0.85(0.61 \text { to } 1.09)^{\mathrm{d}} \\ \text { HDL-C } & -0.50(-1.09 \text { to } 0.10)^{\mathrm{d}} & 0.1012 & -0.42(-1.01 \text { to } 0.17)^{\mathrm{d}}\end{array}$




$\begin{array}{lccc}\text { Non-HDL-C } & 0.95(0.75 \text { to } 1.15)^{\mathrm{d}} & <\mathbf{0 . 0 0 0 1} & 0.88(0.67 \text { to } 1.08)^{\mathrm{d}} \\ \text { Total cholesterol } & 0.87(0.67 \text { to } 1.07)^{\mathrm{d}} & <\mathbf{0 . 0 0 0 1} & 0.81(0.61 \text { to } 1.01)^{\mathrm{d}} \\ \text { Apo-A1 } & 0.34(-0.52 \text { to } 1.20)^{\mathrm{e}} & 0.4371 & 0.60(-0.25 \text { to } 1.45)^{\mathrm{e}} \\ \text { Apo-B } & 4.33(3.42 \text { to } 5.23)^{\mathrm{e}} & \mathbf{< 0 . 0 0 0 1} & 4.04(3.14 \text { to } 4.95)^{\mathrm{e}}\end{array}$

Apo-A1, apolipoprotein A1; Apo-B, apolipoprotein B; BMI, body mass index; CI, confidence interval; DBP, European Study on Cardiovascular Risk Prevention and Management in Usual Daily Practice; HDL-C, highLDL-C, low-density lipoprotein cholesterol; SBP, systolic blood pressure.

${ }^{\mathrm{a}}$ Linear regressions adjusted for sex, age and BMI.

${ }^{b}$ Linear regressions adjusted for sex, age, BMI, statin use, antihypertensive treatment (yes/no), number of car (0/1/2/3 among dyslipidaemia, smoking and diabetes), physical activity and country.

${ }^{\mathrm{c}}$ Significant $P$ values $(<0.05)$ in bold.

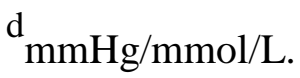

$\mathrm{e}_{\mathrm{mmHg} / \mathrm{g} / \mathrm{L} \text {. }}$ 
TABLE 4. Relationship between blood pressure and serum lipid profile for patients in EURIKA treate

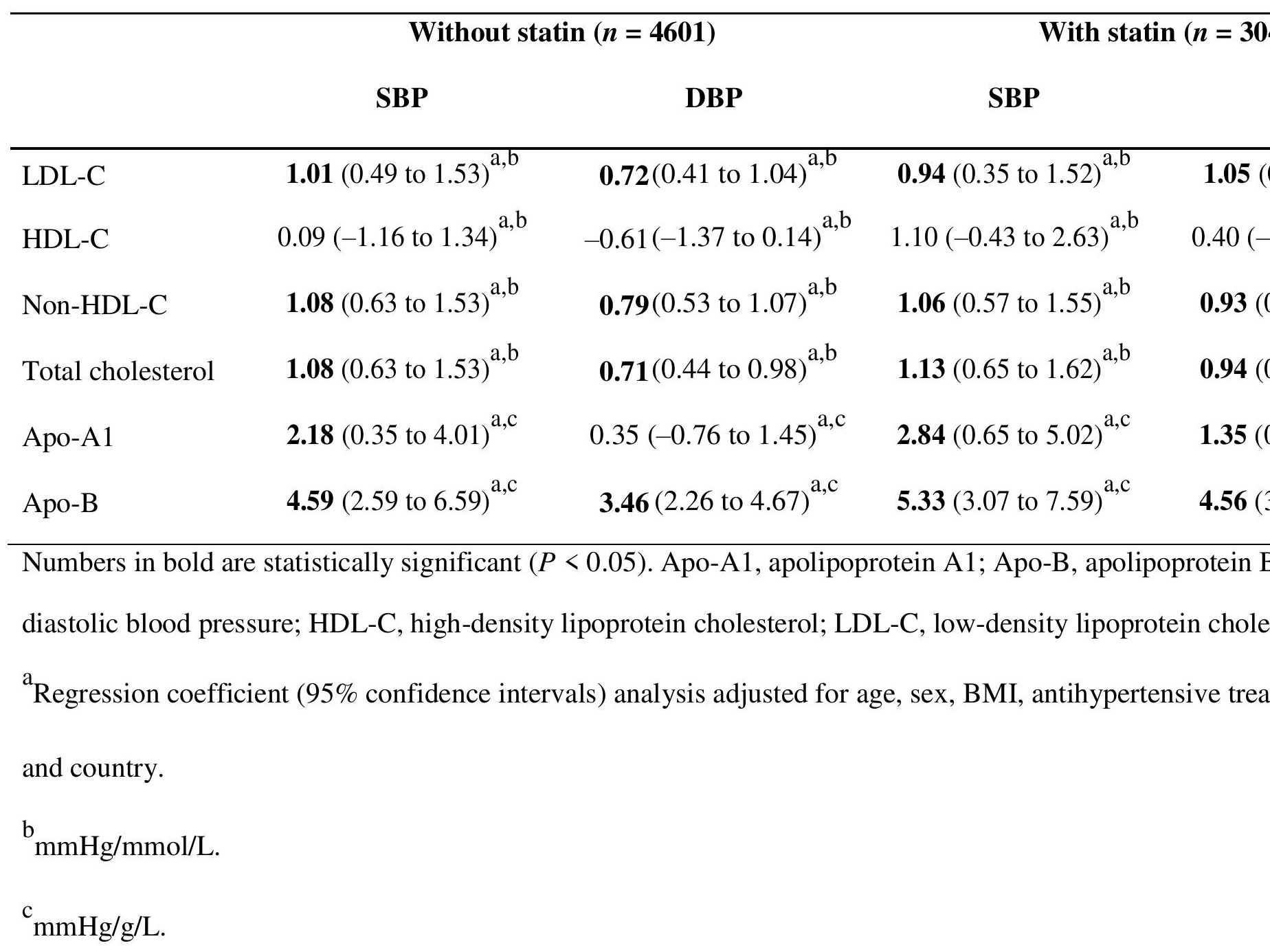


TABLE 5. Relationship between pulse pressure and serum lipid profile for patients in EURIKA treate

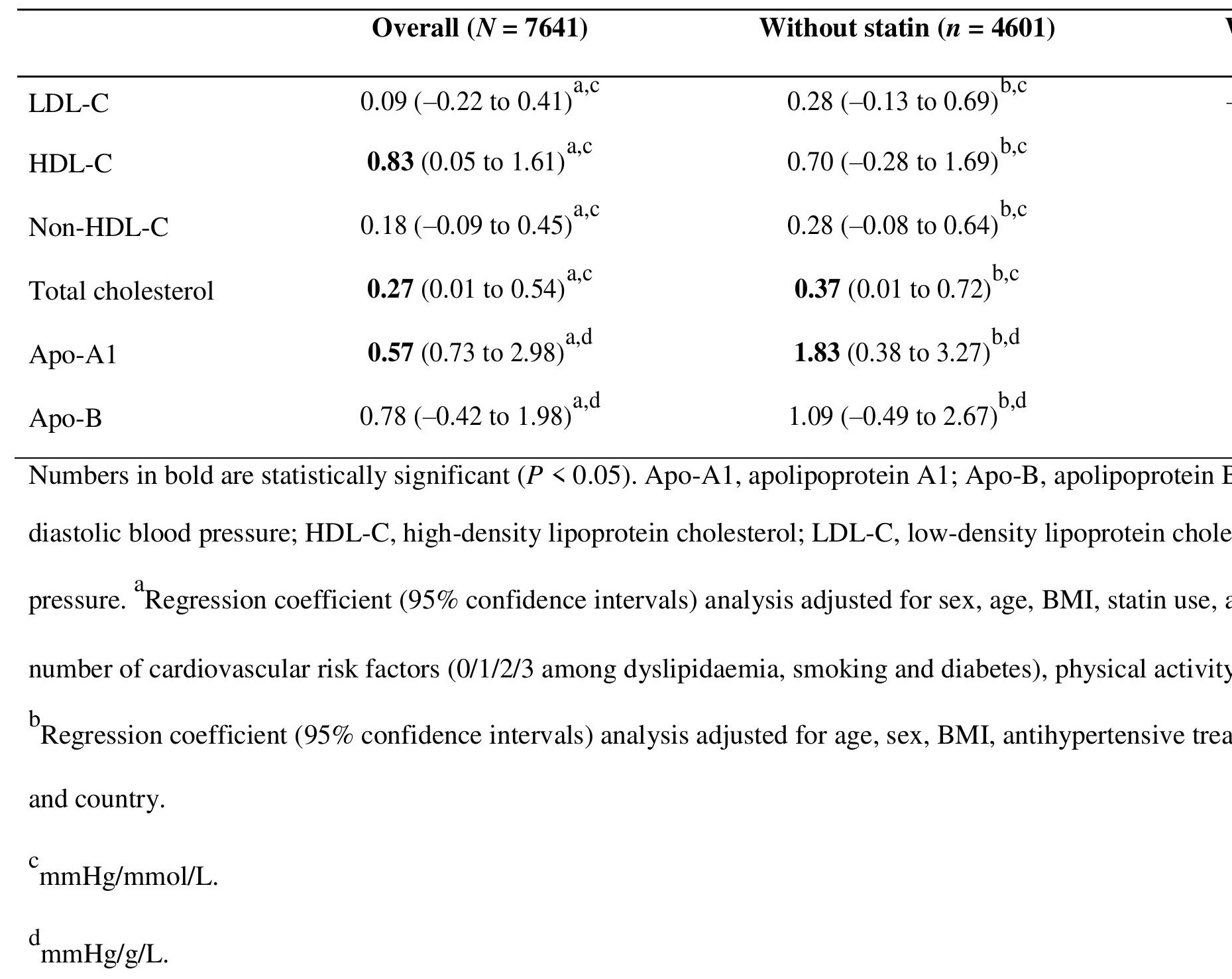


SUPPLEMENTARY TABLE 1. Socio-demographic and clinical characteristics of patients in EURIKA

\begin{tabular}{|c|c|c|c|c|c|c|c|c|c|}
\hline & $\begin{array}{c}\text { Aus } \\
(n=624)\end{array}$ & $\begin{array}{c}\text { Bel } \\
(n=638)\end{array}$ & $\begin{array}{c}\text { Fra } \\
(n=593)\end{array}$ & $\begin{array}{c}\text { Ger } \\
(n=678)\end{array}$ & $\begin{array}{c}\text { Gre } \\
(n=620)\end{array}$ & $\begin{array}{c}\text { Nor } \\
(n=611)\end{array}$ & $\begin{array}{c}\text { Rus } \\
(n=604)\end{array}$ & $\begin{array}{c}\text { Spa } \\
(n=642)\end{array}$ & $\begin{array}{r}\text { Sw } \\
(n=6\end{array}$ \\
\hline Age, mean (SD) & $61.9(8.6)$ & $64.6(8.9)$ & $64.1(8.8)$ & $65.3(8.8)$ & $65.3(8.9)$ & $62.9(8.8)$ & $58.3(7.3)$ & $63.1(9.0)$ & 64.9 \\
\hline \multicolumn{10}{|l|}{ Sex, $n(\%)$} \\
\hline Men & 297 (47.6) & 312 (48.9) & $325(54.8)$ & $333(49.1)$ & $285(46.0)$ & $298(48.8)$ & $192(31.8)$ & $330(51.4)$ & $315(5$ \\
\hline Women & $327(52.4)$ & $326(51.1)$ & $268(45.2)$ & 345 (50.9) & $335(54.0)$ & $313(51.2)$ & $412(68.2)$ & $312(48.6)$ & 313 \\
\hline Hypertension, ${ }^{\mathrm{a}} n(\%)$ & 447 (61.4) & 448 (70.2) & $434(73.2)$ & $549(81.0)$ & 413 (66.6) & $426(69.7)$ & $486(80.5)$ & 435 (67.8) & $516(8$ \\
\hline Dyslipidaemia, ${ }^{\mathrm{b}} n(\%)$ & $359(57.5)$ & 427 (66.9) & $361(60.9)$ & $412(60.8)$ & 457 (73.7) & $401(65.6)$ & $423(70.0)$ & 436 (67.9) & $397(6$ \\
\hline $\begin{array}{l}\text { Hypertension and } \\
\text { dyslipidaemia, } n(\%)\end{array}$ & $269(43.1)$ & $292(45.8)$ & $262(44.2)$ & $334(49.3)$ & $301(48.5)$ & $275(45.0)$ & $353(58.4)$ & $290(45.2)$ & 328 \\
\hline
\end{tabular}

Aus, Australia; Bel, Belgium; DBP, diastolic blood pressure; EURIKA, European Study on Cardiovascular

Usual Daily Practice; Fra, France; Ger, Germany; Gre, Greece; HDL-C, high-density lipoprotein; LD Norway; Rus, Russia; SBP, systolic blood pressure; Spa, Spain; Swe, Sweden; Swi, Switzerland; Tur, Turke ${ }^{\mathrm{a}} \mathrm{SBP} \geq 140 \mathrm{mmHg}$ and/or DBP $\geq 90 \mathrm{mmHg}$ or being treated with one or more antihypertensive drugs.

${ }^{b}$ LDL-C concentration $\geq 4.9 \mathrm{mmol} / \mathrm{L}(190 \mathrm{mg} / \mathrm{dL})$, a serum HDL-C concentration $<1.0 \mathrm{mmol} / \mathrm{L}(40 \mathrm{mg} / \mathrm{dL}) \mathrm{f}$ $\mathrm{mg} / \mathrm{dL}$ ) for women, a non-HDL-C concentration $\geq 5.2 \mathrm{mmol} / \mathrm{L}(200 \mathrm{mg} / \mathrm{dL})$ for $\mathrm{men}$ or $\geq 4.9 \mathrm{mmol} / \mathrm{L}$ (190 mg lipid-lowering medication 


\section{FIGURE LEGENDS}

FIGURE 1 Scatterplots of patients' systolic blood pressure and lipid levels, according to statin treatment. Dotted and solid lines represent regression lines for non-users and users of statins, respectively. Apo-A1, apolipoprotein A1; Apo-B, apolipoprotein B; HDL-C, highdensity lipoprotein cholesterol; LDL-C, low-density lipoprotein cholesterol; SBP, systolic blood pressure.

FIGURE 2 Scatterplots of patients' diastolic blood pressure and lipid levels, according to statin treatment. Dotted and solid lines represent regression lines for non-users and users of statins, respectively. Apo-A1, apolipoprotein A1; Apo-B, apolipoprotein B; DBP, diastolic blood pressure; HDL-C, high-density lipoprotein cholesterol; LDL-C, low-density lipoprotein cholesterol.

FIGURE 3 Scatterplots of patients' pulse pressure and lipid levels, according to statin treatment. Dotted and solid lines represent regression lines for non-users and users of statins, respectively. Apo-A1, apolipoprotein A1; Apo-B, apolipoprotein B; DBP, diastolic blood pressure; HDL-C, high-density lipoprotein cholesterol; LDL-C, low-density lipoprotein cholesterol. 
Figure 1
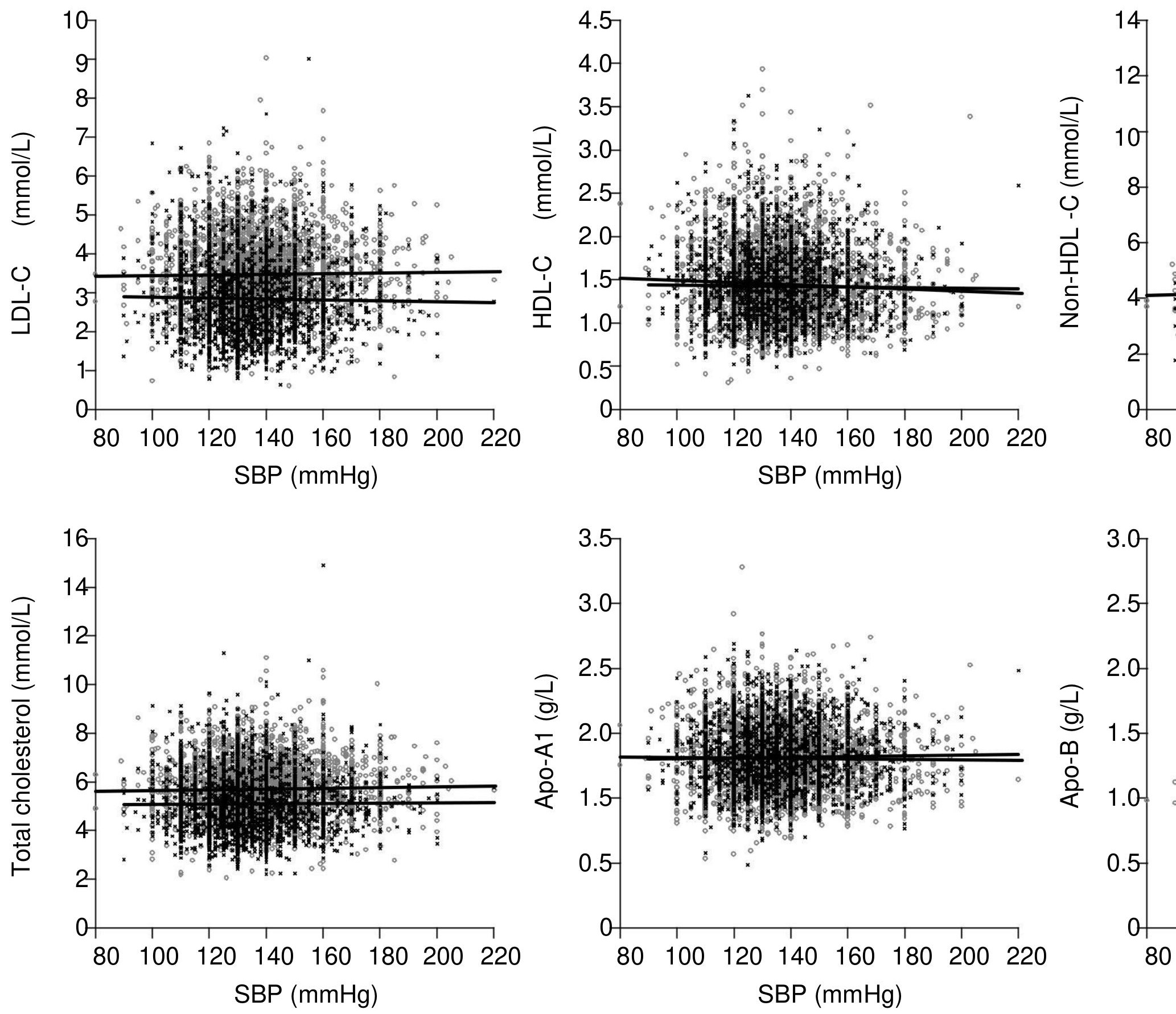

Without statins $\times$ With statins 
Figure 2
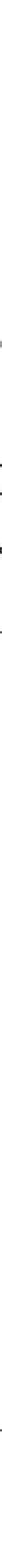

Without statins $\times$ With statins 
Figure 3
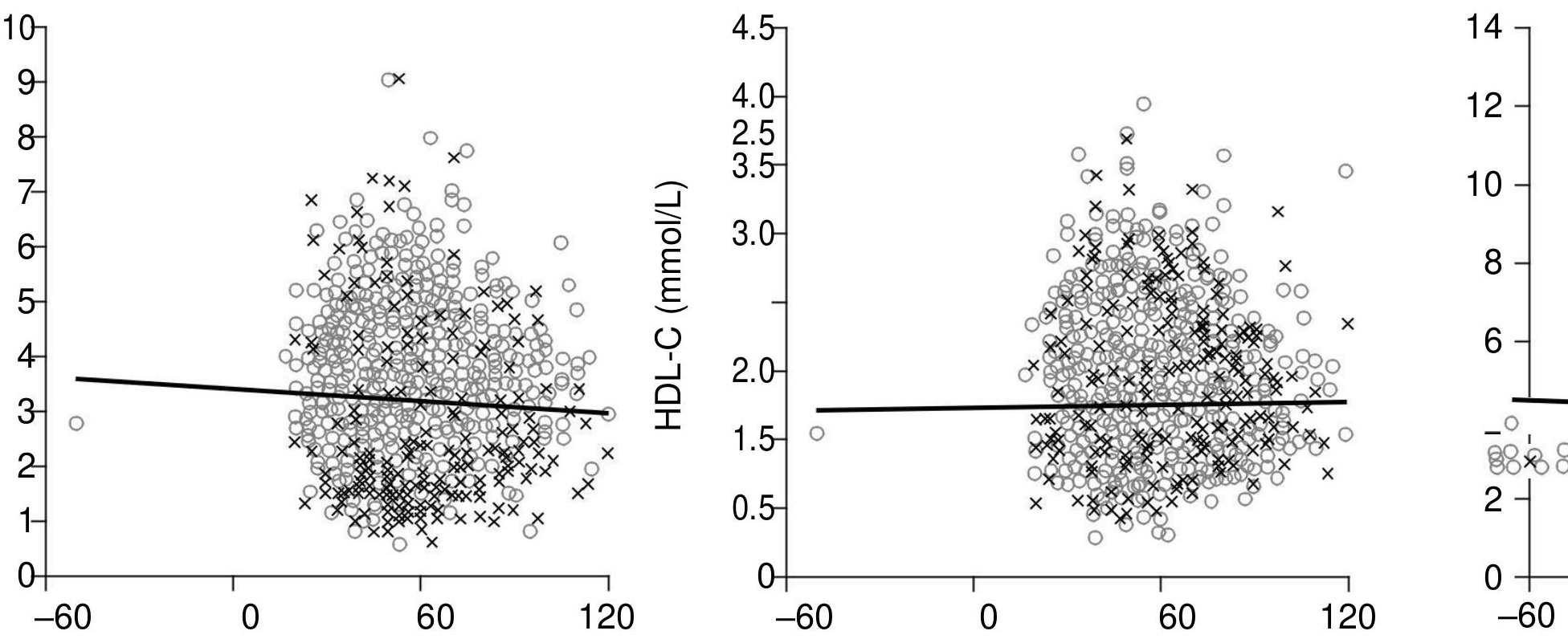

Pulse pressure (SBP - DBP) $(\mathrm{mmHg})$

Pulse pressure (SBP - DBP) $(\mathrm{mmHg})$

$\mathrm{Pu}$
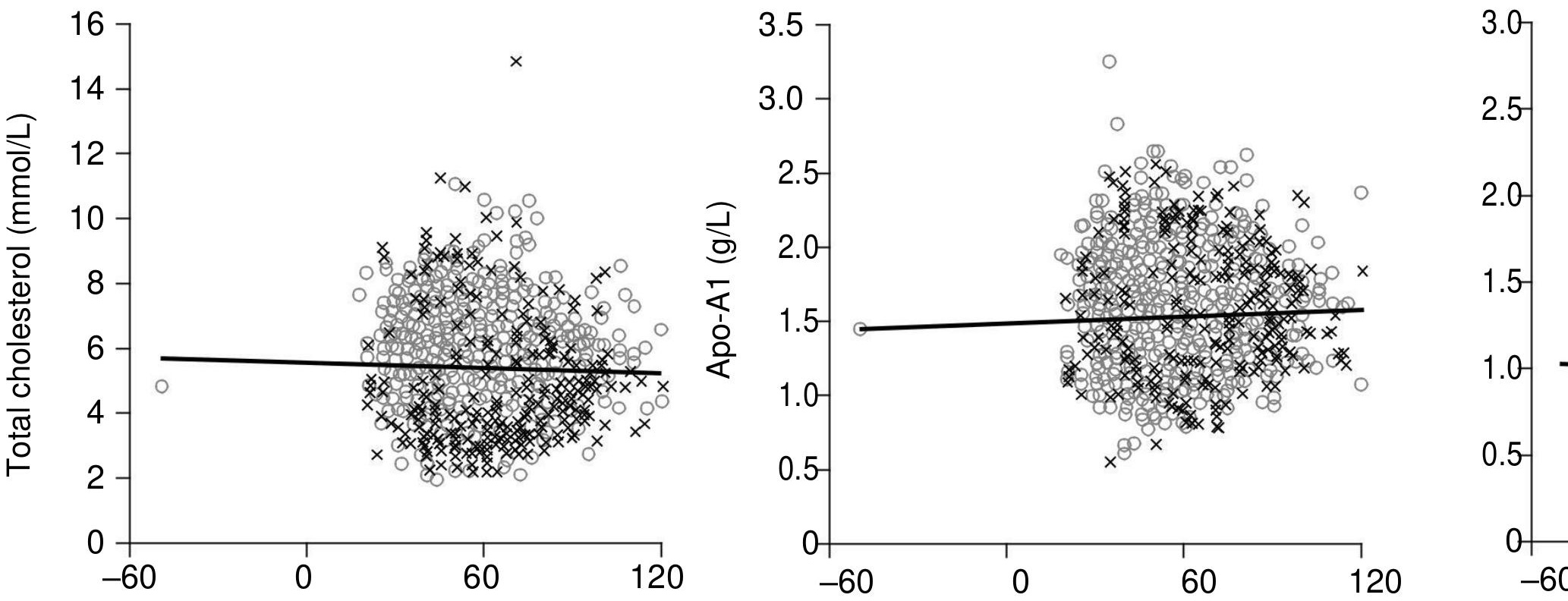

Pulse pressure (SBP - DBP) $(\mathrm{mmHg})$

Pulse pressure (SBP - DBP) $(\mathrm{mmHg})$

$\mathrm{Pu}$

Without statins $\times$ With statins 